\title{
Perswedo: Introducing Persuasive Principles into the Creative Design Process through a Design Card-Set
}

\author{
Xipei Ren ${ }^{1}\left({ }^{\star}\right)$, Yuan $\mathrm{Lu}^{1}$, Harri Oinas-Kukkonen ${ }^{2}$, and Aarnout Brombacher ${ }^{1}$ \\ ${ }^{1}$ Department of Industrial Design, Eindhoven University of Technology, Eindhoven, the \\ Netherlands \\ \{x.ren, y.lu, a.c.brombacher\}@tue.nl \\ ${ }^{2}$ Department of Information Processing Science, University of Oulu, Oulu, Finland \\ harri.oinas-kukkonen@oulu.fi
}

\begin{abstract}
In human-computer interaction (HCI), advances of information and communication technology have led to a wealth of Persuasive Technology (PT) researches to support people's behaviors change. Many PT theories have been widely used for design analysis and are supposed to be useful for PT design. However, very limited effort has been taken to bridge the gap between PT theory and design practice. In this paper, we present the formative study of Perswedo, a card-based tool that introduces persuasive principles from Persuasive Systems Design model to support the creative design flow. As an intermediate step to appropriate Perswedo cards to the design activities, we assessed the usefulness and value of Perswedo in the design process as well as the design implications of the cards through three design workshops. Our findings suggest further study to resonate PT theoretical work with design practice.
\end{abstract}

Keywords. Persuasive principles · Card-based tool $\cdot$ Creative design process

\section{Introduction}

Persuasive Technology (PT), the study about computing technology designed to change people's attitudes and behaviors [1], has been seen great benefits in many application areas such as health [2] and sustainability [3]. Many PT researches have drawn much attention on theoretical works (e.g. $[4,5])$. Amongst those Persuasive Systems Design (PSD) model [6] was developed to support the design of persuasive information systems. In PSD, it highlights the design process with detailed analysis of persuasion context. Furthermore, PSD contains four categories of 28 persuasive principles (seven principles in each category), which by default can inform the design process of persuasive systems [7]. According to Consolvo et al. [5], the enclosure of theoretical framework in technology support everyday behavior change.

Given the growing ubiquity of information systems [8] and the complexity of design practice [9], however, the single use of PSD model in the design process has been criticized for implementing design strategies without the appropriation for the real-life context [10]. Let it alone, the simply use of theoretical knowledge, as Hornecker [11] said, tends to be tedious and overweight in design process. It is acknowledged that the gap 
between theoretical framework and design exercise has been a long-existing issue for PT research [12]. To close the gap, according to Stolterman [9], the use of a new theory has to resonate with the existing design practice.

This requirement led to a rich amount of focus on turning design framework into design tools to support the creative design activities, ranging from a screen-based application to specify the placement of interface elements [13] to a card deck to inform design concepts [14]. Here, we particularly observe that as a lightweight tool bringing information into the design flow, card-sets have been complimented to be more affordable in the creative process than other means of tools [11]. Bekker and Antle [15] suggested cards as a tool for designers to use both for accessing knowledge and for supporting the existing way they work in design practice. Therefore, we employed a similar approach to examine if the transformation of persuasive principles into card-based design tools could be useful and valuable for the creative design process of interactive technology.

In this paper, we present a formative study of Perswedo, a card-format design tool that derives from PSD model. The paper proceeds as follows. Next section we explain in detail how we designed Perswedo, which is followed by the setup of our evaluation in Section 3. This results in the analysis on the usefulness, value, and implications of our current design in Section 4. Conclusions are given in the end.

\section{Perswedo Cards}

\subsection{Persuasive Principles from PSD}

PT is described as "any interactive computing system designed to change people's attitudes or behaviors" [16]. Based on Fogg's work [1], Oinas-Kukkonen and Harjumaa [6] conceptualized the PSD model. The model puts emphasis on detailed and rigorous analysis of the persuasion context from figuring out the intended types of behavior change, to identifying the events of use and users of technologies, to developing the strategies and delivery route to the target users. Moreover, PSD established four categories of persuasive principles (partly derived from Fogg's theory [1]), namely: primary task, system credibility, dialogue and social support. Primary task support typically simplifies or facilitates certain activities; System credibility support aims to influence user through increasing system credibility in various manners. Dialogue support enhances user-computer communications to keep users moving towards target behavior. Social support leverages user's motivation with the help of social factors. In this study, our scope was to introduce PT knowledge into the design of interactive technology. We exclusively selected the categories of dialogue support and social support to develop the card-set, as they are the features that mostly relevant to technology-mediated interaction design [7] and have been widely applied in diverse design topics, such as games [17]. The principles that are addressed by our initial card-set are:

- Dialogue support: praise, similarity, reward, liking, reminder, social role, suggestion. 
- Social support: social facilitation, recognition, social learning, cooperation, competition, social comparison, normative influence.

\subsection{Turning Principles into Perswedo Cards}

This study aimed to design Perswedo cards as a domain specific carrier [18] bringing PT design principles into design processes. For this purpose, we firstly explored how to convert the knowledge from PSD into the information on the cards. Based on the literature review and the interview with eight design researchers, we designed Perswedo cards (Figure 1, available from goo.gl/H7JblW) with the following focuses:
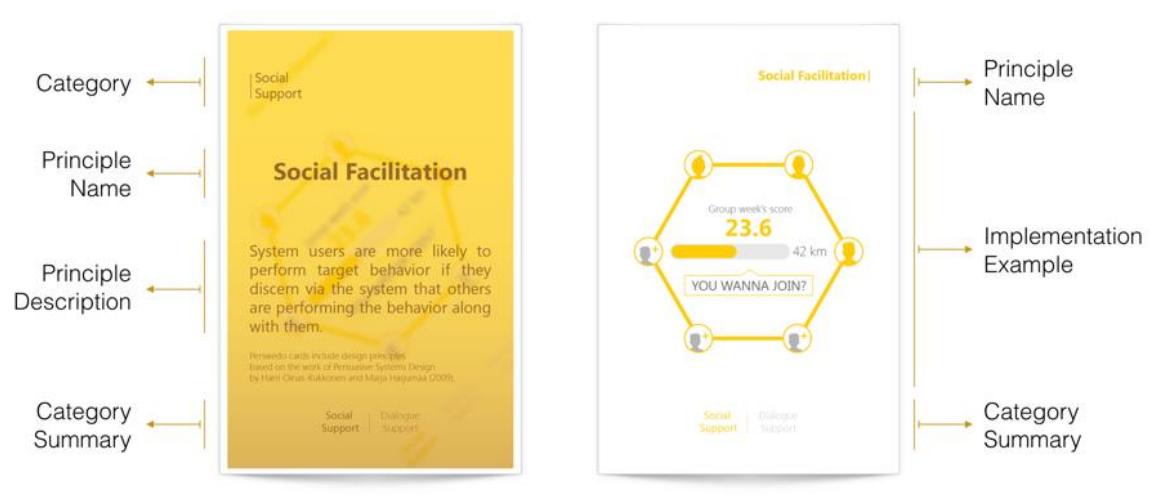

Fig. 1. A Perswedo Card from Social support category

- General Contents: The same as most of the cards [11, 15, 19-21], each Perswedo card includes both text of the principle to provide adequate information [19], and illustration of the example to allow an open interpretation [15];

- Text: The description of each principle was displayed directly on the front side of the card, as it clearly explains the principle in one simple sentence [6]. This was also confirmed during our interviews;

- Illustration: On the back side of the cards, advised by [15], we designed all the illustrations on the basis of people's everyday technology-mediated physical activity referring to the example requirement from PSD [22]. Two design researchers checked the consistency between example illustrations and principle descriptions on every individual Perswedo card for us.

- Categorization: Similar to previous works [11, 15, 19, 23], Perswedo cards were color-coded by different categories. The green color was selected for seven dialogue support cards and yellow color was selected for seven social support cards. Moreover, the name of the current principle and the host category were also placed properly on each card to support designers to distinguish cards without too much effort.

- Format: We made each card approximately 3.0 " by 4.4 " in size to be flexible enough in various design activities. Furthermore, Perswedo cards were printed on PVC, which makes the cards easy to clean and more durable to use. 


\section{Evaluation}

We introduced Perswedo cards in three design workshops to: (I) Examine if current Perswedo Cards are useful in supporting the creative design process; (II) Understand what kind of values can Perswedo cards offer in the design flow; (III) Find design challenges for Perswedo to enlighten next step.

\subsection{Participants}

We conducted three workshops in three different universities. Workshop A comprised 19 postgraduate students ( 10 females and 9 males; Age: $\mathrm{M}=25.5, \mathrm{SD}=4.0$ ) from the interaction design program. Five of them used to be designers (min: 1year, max: 11year). Workshop B was carried out with 13 senior bachelor students (6 females and 7 males; Age: $\mathrm{M}=23.2, \mathrm{SD}=1.3$ ) from the interaction design program. All of them had at least half year experience as a design intern in the industry. In workshop C, 18 bachelor students ( 8 females and 10 males; Age: $\mathrm{M}=21.4, \mathrm{SD}=2.1$ ) studied interaction design for one year as electives. They were from different bachelor school ranged from electrical engineering, mechanical engineering, architecture, agriculture, finance, and linguistics, etc. Similar to [19], here we refer them as advanced group (from workshop A), intermediate group (from workshop B), and elementary group (from workshop C) with respect to their experience in interaction design.

\subsection{Procedures}

At the beginning, we allocated students into working groups with size between 5 and 7 persons per group. In all the workshops, participants were asked to design interactive technology for healthy aging. Given the broadness of this topic, students were later dived in several related fields, such as physical activity, food, medication, and healthcare for elderly people. The procedure for three design workshops was very similar: workshop A and C lasted seven consecutive days, while workshop B were split into one day per week in seven weeks. In each workshop, students followed the typical creative design process [24], from analyzing the problem to generating concept, to implementing design (low-fidelity), where we introduced Perswedo after the first stage.

Perswedo cards were introduced with a presentation given by us. We firstly introduced PT, PSD, and persuasive principles to all the participants. We followed by presenting Perswedo cards with a basic instruction to show how to use them in the design process. We also arranged some "warm-up" sessions to facilitate the use of the cards. After then, each group kept one set of Perswedo cards until the end of the workshop.

\subsection{Data Collection}

We collected data using a combination of survey and observation methods. After the workshops, all the participants were asked to fill in a questionnaire with a 5-point Likert Scale, with 5 being strongly agree, it is consisted of five items adopted from [21] to 
examine if Perswedo cards were helpful to (i) improve idea; (ii) generate idea; (iii) get the group focus on the topic; (iv) articulate the concept; (v) get the team to consensus on the discussion. Moreover, similar to [19], it asked participants to rate the usefulness of the cards by different elements, including the card format, the principle description, and the design example. In the end, we gave options for participants to leave comments for what values they found about using Perswedo in the design process. Furthermore, they were asked to give suggestions on the current design and usage of Perswedo. We also captured photo and video here to compensate our survey data.

\section{$4 \quad$ Results}

From three workshops, we collected 50 responses on the post-questionnaire. 38 among them stated values of the cards in design process, where 21 participants gave additional suggestions to inform our further iteration. In what follows, we present our findings in three folds. To start, we report the quantitative results from the scale to show how our participants assessed the usefulness of Perswedo in the design process. We then cluster the qualitative data based on the logical closeness of different results, where we firstly describe extra values of Perswedo we found from the questionnaire. We end up by presenting the design implications for current cards, which we have to take into account for the further appropriation of Perswedo cards into design practice.

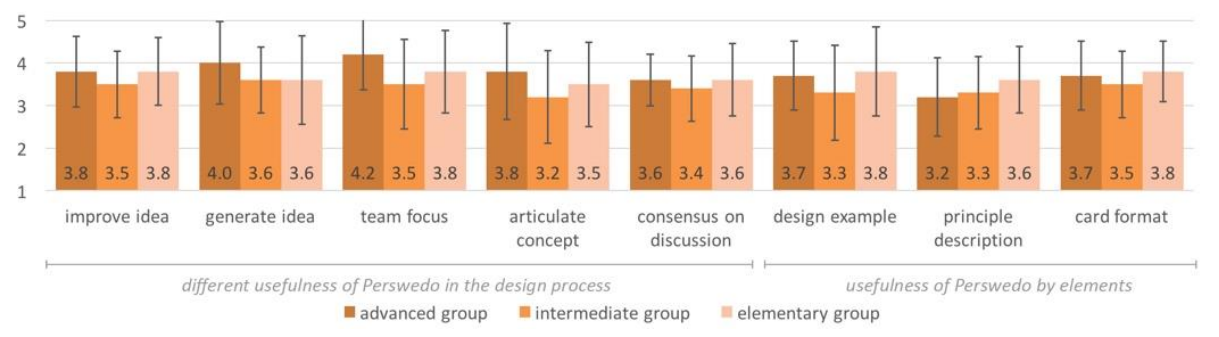

Fig. 2. Participants' average ratings on Perswedo cards from the scale by groups.

\subsection{Usefulness of Perswedo}

Our questionnaire data (Figure 2) indicate that on average the participants rated the usefulness better than neutral. Which implies Perswedo cards were supportive in different design activities for both individual and group. Moreover, it suggests that different elements of the cards positively supported the usage of Perswedo in the design flow. Given the small and uneven group size, it is unwarranted to compare the difference between three groups. However, from the chart we observed that the advanced group in general gave the most optimistic feedback on the questionnaire, despite they found the descriptions of the persuasive principles were least useful among others. One interpretation of this is perhaps this group of designers were familiar with how cards work in the design process so that they made use of the cards easier in the relatively short time in the workshop. Yet the textual content was less informative for them, as they 
might already know PT theory beforehand. Furthermore, the intermediate group scored the usefulness of Perswedo the lowest among most of the items, which suggest no liner correlation between the design knowledge and the perceived usefulness of the cards.

\subsection{Value of Perswedo}

(V1) scope the design directions. The results suggest that Perswedo was helpful to orient the design progress, as one participant mentioned: [Perswedo] gives us a basic foundation to start, as it's easy to start from the words. This could be dated back to PSD, in which every principle has been summarized into a keyword [6]. In this way, it helps people to grasp the core meanings of different design guidelines in a nutshell. Moreover, most of the participants appreciated the way how PSD classified design principles. They thought two perspectives, both dialogue support and social support, were very easy to understand and useful in guiding design. Participants also stated that colorcode clearly differentiated two categories with each other. Also, our explanation in the beginning helped them a more comprehensive understanding of the classification.

(V2) expand ways for concept development. In addition, 13 participants mentioned that cards were well designed and were clearly easy to use and consequently helped them to generate new ideas out of the box, as Perswedo inspired some [persuasive]directions of the design, which sometimes can be forgotten. Some participants even thought the cards provoked a sort of challenge, which stimulated them to think about a more varied approach of persuasion. Some others believed that Perswedo led them to talk about project [more] openness. Moreover, by acting with multiple cards, it gave external support to expand design rationale, as one student mentioned: when combining some cards together with each other, it helps to develop more possibilities. On the flip side, four participants also left comment that the cards helped the team more focus on the exact topic. They realized that when choosing a card, you had a specific purpose for the concept. Furthermore, information on the cards also helped students to weigh up their existing ideas, as one participant said: Explanation [on the cards] was a great help to confirm ideas on behavior change.

(V3) extra values of the cards: improve design activities. Besides the dual-role of Perswedo we found as a domain knowledge carrier [18] to scope and expand the design thinking, we observed Perswedo, as a card-based tool for co-design practice, leveraged teamwork in three ways: Firstly, as a physical material for collaboration, Perswedo could be good incentives to start group discussion; Secondly, many participants considered the cards had assisted them to structure team discussion in a more well-organized way; Thirdly, since our tool helped students to be more focus on think, draw, and share during the project, they believed it also provided them an occasion to identify individual's expertise, and in return to learn from each other.

Moreover, we found that nature of design card-set allowed participants to elaborate their ideas in different sessions by multiple manipulations. For instance: By placing the cards on sketching paper, participants figured out their concept more concretely; By 
pointing at different cards during discussion, participants communicated their idea more precisely; By linking their work with different principles in the pitch, participants presented their design more clearly; by holding the cards in their hand, participants felt more confident to tell us the story of the concept based on the design guidelines.

\subsection{Design Implications for Perswedo}

Despite the advantages of using Perswedo, we also learned our participants sometimes encountered difficulties to understand and use the cards as well as the PSD theory properly in the design process. Similar as what have been revealed previously [21], our approach of simplifying and abstracting the theoretical framework could bring danger to hinder or mislead design activities. Therefore, in the following we elaborate on what need to be done further to bring persuasive principles more appropriate to the actual design activities.

(I1) design example: topic relevance. During workshops, three participants mentioned that the examples we offered on the cards, mostly about to motivate physical activity, were not always relevant to their design topics. Therefore, they suggested us to redesign examples to enable broader use of Perswedo. For instance, some students expected to get the real cases from designers or experts as references. Some students came to think of depicting more information on the backside, such as offering two examples for two directions on the back. From what participants suggested, showing multiple examples from various directions instead of single case on the cards would make the cards more inclusive to use in different design activities. In addition, prior studies [25] inform us that enabling the customization of Perswedo could also improve a wider usage in design process. To make the cards customizable, for instance, we can offer a DIY service platform with a database so that the content of the cards can be adapted for different use. Another example will be leaving the editable space on the cards, where designers can add their own interest.

(I2) persuasive principles: generative and informative. In terms of the principle descriptions, some participants complained: The descriptions are not easy to understand when I first read them. Hence, their discussion sometimes focuses on the cards instead of on the idea for design project. From the feedback, we also learned that some design principles in PSD were very similar for our participants and somehow might confuse them during the usage. If we look back to PSD model itself, even though some principles look similar to each other from the descriptions, the principles are actually distinct to each other from the psychological perspective. For example, the meaning of $r e-$ minder and suggestion are quite close. However, reminder is suggested to use for people who have a goal in their mind, while suggestion is more likely to introduce certain behavior to people who have no goal so far. Therefore, it is necessary to introduce more comprehensive story of the theory to our audience. To do so, supplementary tools, such as booklets, articles, and websites, that explain the story in detail should be added into 
the ecology surrounds our cards. Moreover, the foldable cards with space for more information could be another interesting direction to explore. Additionally, we also have interest to explore layman terms for persuasive principles so that more people with different background can use it without much confusion. Provocative content on the cards, such as transforming the guidelines into colloquial questions [11,21], is also effective to facilitate the creative process.

(I3) language variations. Since our participants were not all from English speaking countries, their fluencies in English were quite different. Therefore, the participants, who were not used of English as working language, had hard time to understand the meaning of Perswedo, as they stated: For the tester whose mother tone isn't English, it's needed some times to understand the text on the card. Some of them also noted that they could only refer to the graphics while using the cards. We have to admit that we overlooked the language issue when developing Perswedo. However, our participants considered that there should be a way for Perswedo to cross the culture and language. Despite the ordinary way to translate PSD principles into different versions, some students suggested more icons or info-graphics [on the cards] will [help designers] to understand [the concept] more clearly and instantly. Which means there is a chance to use visual elements to optimize the interaction between users and Perswedo.

\section{Conclusions}

In this paper, Perswedo cards are developed to support flexible access to the persuasive principles from PSD in the creative design process. As a work to close the gap between PT theory and design practice, we reflect on what we learned here to discuss on the role of card-based PSD and the challenges of using PSD in the creative design.

Although PT theories have been critiqued for prescribing behavioral change strategies [10] and unreflective in defining behavior changes [26], similar to [12], our study reveals the proper inclusion of PT knowledge can inform the design process. Our participants assessed the cards and the individual element were useful in different activities, which indicated the potential usefulness of PSD framework in the design practice. This was achieved by the card-formal presentation of PSD supported the participants to scope the design directions and to expand the concept development.

However, we have to admit the current design and usage of Perswedo cards still lack considerations to appropriate PSD more into the design flow. As mentioned earlier, this study implies the further improvement of Perswedo by focusing on topic relevance in design examples, informative and generative in principle descriptions, and language variations. More importantly, according to [11], the design cards alone are not a method itself. The specific mechanisms and design methods would support generative use of theoretical framework [20]. Similarly, our participants suggested us to integrate cards into toolkit or structured design approach to instruct the use of persuasive principles. Therefore, this study reveals the challenge that designers need to remain openness to any supportive design methods while using card-based PSD principles in the design process. 
In the future, we firstly plan to improve the card design of Perswedo based on the design implications from this study. We then plan to further associate Perswedo cards with other cards-sets, such as context information [25] and design methods [14], to improve the use of PT theories in the co-design practice. The new version of Perswedo will be evaluated in professional design projects, which will have more thorough process to follow. Moreover, we will also bring the cards into several workshops to see how PSD knowledge will influence users and stakeholders to design PT in the participatory design [12].

Acknowledgment. The first author of this paper is being sponsored by China Scholarship Council. We thank all participants who volunteered to take part in the studies. A special thanks to Vincent Visser for your help to organize the workshops.

\section{Reference}

1. Fogg, B.: Persuasive technology: using computers to change what we think and do. Morgan Kaufmann Publishers (2003).

2. Lin, J.J., Mamykina, L., Lindtner, S., Delajoux, G., Strub, H.B.: Fish'n'Steps: Encouraging Physical Activity with an Interactive Computer Game. In: UbiComp 2006: Ubiquitous Computing. pp. 261-278 (2006).

3. He, H., Greenberg, S., Huang, E.: One size does not fit all: applying the transtheoretical model to energy feedback technology design. ... 28th Int. Conf. .... 927-936 (2010).

4. Hekler, E.B., Klasnja, P., Froehlich, J.E., Buman, M.P.: Mind the Theoretical Gap: Interpreting, Using, and Developing Behavioral Theory in HCI Research. Proc. CHI 2013. 3307-3316 (2013).

5. Consolvo, S., McDonald, D.W., Landay, J. a.: Theory-driven design strategies for technologies that support behavior change in everyday life. In: Proceedings of the 27th international conference on Human factors in computing systems - CHI 09. pp. 405-414 (2009).

6. Oinas-Kukkonen, H., Harjumaa, M.: Persuasive systems design: Key issues, process model, and system features. Commun. Assoc. Inf. Syst. 24, 485-500 (2009).

7. Torning, K., Oinas-Kukkonen, H.: Persuasive System Design: State of the Art and Future Directions. Persuas. '09 Proc. 4th Int. Conf. Persuas. Technol. 1 (2009).

8. Oinas-Kukkonen, H.: A foundation for the study of behavior change support systems. Pers. Ubiquitous Comput. 17, 1223-1235 (2012).

9. Stolterman, E.: The nature of design practice and implications for interaction design research. Int. J. Des. 2, 55-65 (2008).

10. Purpura, S., Schwanda, V., Williams, K., Stubler, W., Sengers, P.: Fit4life: The design of a persuasive technology promoting healthy behavior and ideal weight. Proc. 2011 Annu. Conf. Hum. factors Comput. Syst. - CHI '11. 423 (2011).

11. Hornecker, E.: Creative idea exploration within the structure of a guiding framework: the card brainstorming game. Proc. fourth Int. Conf. Tangible Embed. embodied Interact. 10, 101-108 (2010).

12. Davis, J.: Early Experiences with Participation in Persuasive Technology Design. Proc. 12th Particip. Des. Conf. Res. Pap. 1, 119-128 (2012). 
13. Li, Y., Landay, J. a: Activity-based prototyping of ubicomp applications for long-lived, everyday human activities. Proc. ACM CHI 2008 Conf. Hum. Factors Comput. Syst. 1, 1303-1312 (2008).

14. Guterman, J.: IDEO Method Cards., http://www.redibw.de/db/ebsco.php/search.ebscohost.com/login.aspx\%3Fdirect\%3Dtrue\%26db\%3Dbth\% 26AN\%3D51605598\%26site\%3Dehost-live, (2010).

15. Bekker, M.M., Antle, A.N.: Developmentally Situated Design ( DSD ): Making Theoretical Knowledge Accessible to Designers of Children 's Technology. CHI 2011 Conf. 25312540 (2011).

16. Fogg, B.: Persuasive computers: perspectives and research directions. ... SIGCHI Conf. Hum. factors Comput. .... 98, 225-232 (1998).

17. Alahäivälä, T., Oinas-Kukkonen, H.: Understanding persuasion contexts in health gamification: A systematic analysis of gamified health behavior change support systems literature, (2015).

18. Wölfel, C., Merritt, T.: Method Card Design Dimensions : A Survey of Card-Based Design Tools. 479-486 (2013).

19. Deng, Y., Antle, A.N., Neustaedter, C.: Tango Cards: A Card-Based Design Tool for Informing the Design of Tangible Learning Games. (2014).

20. Lucero, A., Arrasvuori, J.: PLEX Cards : A Source of Inspiration When Designing for Playfulness. Fun Games. 15, 28-37 (2010).

21. Mueller, F.F., Gibbs, M.R., Vetere, F., Edge, D.: Supporting the Creative Game Design Process with Exertion Cards. 2211-2220 (2014).

22. Matthews, J., Win, K.T., Oinas-Kukkonen, H., Freeman, M.: Persuasive Technology in Mobile Applications Promoting Physical Activity: a Systematic Review. J. Med. Syst. 40, (2016).

23. Lucero, A.: PLEX Cards : A Source of Inspiration When Designing for Playfulness. 28-37 (2010).

24. Warr, A., O’Neill, E.: Understanding design as a social creative process. Proc. 5th Conf. Creat. Cogn. 118-127 (2005).

25. Halskov, K., Dalsgård, P.: Inspiration card workshops. Proc. 6th Conf. Des. Interact. Syst. 2-11 (2006).

26. Brynjarsdottir, H., Håkansson, M., Pierce, J., Baumer, E., DiSalvo, C., Sengers, P.: Sustainably unpersuaded: How Persuasion Narrows Our Vision of Sustainability. Proc. 2012 ACM Annu. Conf. Hum. Factors Comput. Syst. - CHI '12. 947 (2012). 